\title{
Signet Ring Cell Carcinoma Finding after Thoracentesis: When a Routine Procedure Reveals Something Else
}

\author{
(1) Pedro Daniel Landa-Alvarado1, (1) Ana Lilia Rayas-Gómez², (D) José Manuel González-Rayas³, (1) José Manuel González-Yáñez4 \\ 1San José de Querétaro Hospital, Clinic of Pneumology Private Practice, Querétaro, México \\ 2San José de Querétaro Hospital, Clinic of Cardiology/Echocardiography Private Practice, Querétaro, México \\ 3 Monterrey Institute of Technology and Higher Education Faculty of Medicine, Monterrey, México \\ 4San José de Querétaro Hospital, Clinic of General Surgery/Vascular and Endovascular Surgery Private Practice, Querétaro, México
}

\section{Image Discussion}

An 83-year-old male consulted the cardiologist for New York Heart Association functional classification functional class deterioration, anemia and chronic fatigue. He had a history of heart failure with preserved ejection fraction, Diabetes Mellitus, dyslipidemia, hyperuricemia, primary hypothyroidism, herpetiform dermatitis, alleged Sjögren's syndrome, arterial hypertension, hypertensive heart disease, mitral sclerosis with mild regurgitation, ischemic cardiomyopathy (present unstable angina and past myocardial infarction), stent placement in the left anterior descending artery, transient ischemic attack and bilateral carotid disease treated by angioplasty and stenting.

Two weeks earlier the patient complained about chest pain, dyspnea and cough with hyaline expectoration. He was diagnosed with community acquired pneumonia and received antibiotics, reporting incomplete clinical improvement. The day of the consult, transthoracic echocardiography revealed a bilateral parapneumonic pleural effusion (PPE). The patient was admitted and referred to the pneumologist, who performed a thoracentesis and extracted $1.420 \mathrm{~mL}$ of mildly hematic liquid. Laboratory examination gave the result of cellular atypia. Hence, samples from right and left effusions were sent for pathology assessment, reporting evidence of numerous epithelial cells distributed in small groups in isolation. They presented eccentric nuclei, clear cytoplasm with vacuolated aspect, and some adopted the form of signet ring cells (SRC). The specimen was positive for malignant neoplastic elements, compatible with SRC adenocarcinoma (Figure 1). The patient decided not to continue with the diagnostic procedure and was discharged.

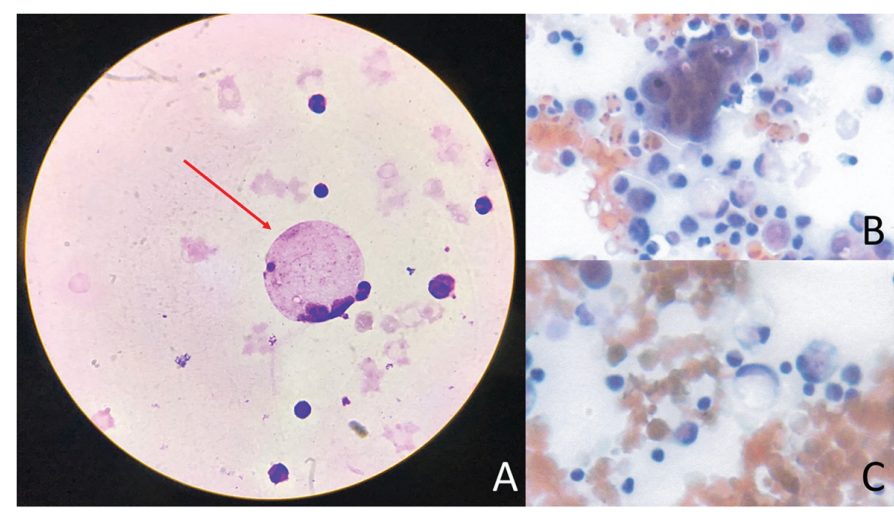

Figure 1. A) Cellular atypia later identified as signet ring cell adenocarcinoma. Various cells with the same morphology were found on the initial pleural effusion analysis by the clinical laboratory. Gram stain, 40x. B) Left pleural effusion pathology analysis. Papanicolaou stain, 40x. C) Right pleural pathology analysis. Papanicolaou stain, 40x

SRC carcinoma is a subtype of mucin-producing adenocarcinoma. It is rare, aggressive, poorly differentiated and often originates from the gastrointestinal tract (1). Furthermore, it has a late presentation and carries a poor prognosis (1). According to the guidelines, PPE's treated with antibiotics that show a poor evolution need a prompt clinical reassessment, analysis of a sample of the fluid (repeat if previously collected) and, probably, effusion drainage by chest tube (2). Hence, since the patient presented a poor clinical progress in spite of being treated with antibiotics, we decided to drain the PPE by needle aspiration, with good results. Thus, we believe that PPE drainage in old patients with unsatisfactory clinical evolution is justified, adding symptomatic improvement and the possibility of discovering hidden pathologies like neoplasia. Finally, this case is a reminder

Address for Correspondence: José Manuel González-Rayas, Monterrey Institute of Technology and Higher Education Faculty of Medicine, Monterrey, México

Phone: +52 8183582000 E-mail: contact.jmgr@gmail.com ORCID: orcid.org/0000-0003-3035-6609

Received: 30 Jan, 2020 Accepted: 03 Feb, 2020

Cite this article as: Landa- Alvarado PD, Rayas-Gómez AL, González-Rayas JM, González-Yáñez JM. Signet Ring Cell Carcinoma Finding after Thoracentesis: When a Routine Procedure Reveals Something Else. Eur J Geriatr Gerontol 2020;2(2):58-59

๑Copyright 2020 by the Academic Geriatrics Society / European Journal of Geriatrics and Gerontology published by Galenos Publishing House. 
that should alert us to consider the presence of malignancies as the cause of clinically unwell elder patients when other conditions are ruled out.

Keywords: Signet ring cell carcinoma, thoracentesis, old age, parapneumonic pleural effusion

\section{Ethics}

Informed Consent: Written consent was obtained.

Peer-review: Internally peer-reviewed.

\section{Authorship Contributions}

Surgical and Medical Practices: P.D.L.A., A.L.R.G., Concept: P.D.L.A., A.L.R.G., J.M.G.R., J.M.G.Y., Design: J.M.G.R., J.M.G.Y.,
Data Collection or Processing: P.D.L.A., A.L.R.G., J.M.G.R., Analysis or Interpretation: P.D.L.A., A.L.R.G., J.M.G.R., Literature Search: J.M.G.R., Writing: J.M.G.R.

Conflict of Interest: The authors declare no conflict of interest.

Financial Disclosure: The present article received no specific funding.

\section{References}

1. Al-Taee A, Almukhtar R, Lai J, Jallad B. Metastatic signet ring cell carcinoma of unknown primary origin: a case report and review of the literature. Ann Transl Med 2016;4:283.

2. Davies HE, Davies RJO, Davies CWH, BTS Pleural Disease Guideline Group. Management of pleural infection in adults: British Thoracic Society pleural disease guideline 2010. Thorax 2010;65(Suppl 2):41-53. 